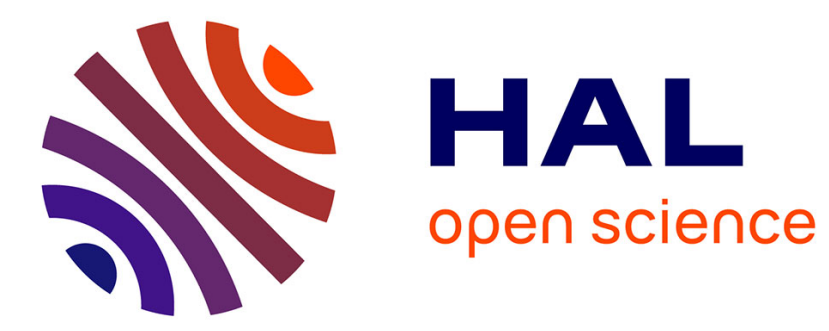

\title{
Mass measurement of short-lived halo nuclides
}

\author{
C. Bachelet, G. Audi, C. Gaulard, C. Guenaut, F. Herfurth, D. Lunney, M. de \\ Saint Simon, C. Thibault
}

\section{To cite this version:}

C. Bachelet, G. Audi, C. Gaulard, C. Guenaut, F. Herfurth, et al.. Mass measurement of shortlived halo nuclides. ENAM 04 The Fourth International Conference on Exotic Nuclei and Atomic Masses, Sep 2004, Pine Mountain, Georgia, United States. pp.31-32, 10.1140/epjad/i2005-06-005-5 . in2p3-00024343

\section{HAL Id: in2p3-00024343 https://hal.in2p3.fr/in2p3-00024343}

Submitted on 6 Jul 2005

HAL is a multi-disciplinary open access archive for the deposit and dissemination of scientific research documents, whether they are published or not. The documents may come from teaching and research institutions in France or abroad, or from public or private research centers.
L'archive ouverte pluridisciplinaire HAL, est destinée au dépôt et à la diffusion de documents scientifiques de niveau recherche, publiés ou non, émanant des établissements d'enseignement et de recherche français ou étrangers, des laboratoires publics ou privés. 


\title{
Mass measurement of short-lived halo nuclides
}

\author{
C. Bachelet ${ }^{1}$, G. Audi ${ }^{1}$, C. Gaulard ${ }^{1}$, C. Guénaut ${ }^{1}$, F. Herfurth ${ }^{2}$, D. Lunney $^{1}$, M. De Saint Simon ${ }^{1}$, C. Thibault ${ }^{1}$,
} and the ISOLDE Collaboration ${ }^{3}$

1 CSNSM-IN2P3-CNRS, F-91405 Orsay-Campus, France

2 GSI Planckstraße 1, 64291 Darmstadt, Germany

${ }^{3}$ CERN, CH-1211 Geneva 23, Switzerland

Received: date / Revised version: date

\begin{abstract}
A direct mass measurement of the very-short-lived halo nuclide ${ }^{11} \mathrm{Li}\left(\mathrm{T}_{1 / 2}=8.7 \mathrm{~ms}\right)$ has been performed with the transmission mass spectrometer MISTRAL. The preliminary result for the two-neutron separation energy is $S_{2 n}=376 \pm 5 \mathrm{keV}$, improving the precision seven times with an increase of $20 \%$ compared to the previous value [1]. In order to confirm this value, the mass excess of ${ }^{11} \mathrm{Be}$ has also been measured, $M E=20171 \pm 4 \mathrm{keV}$, in good agreement with the previous value $[2,3]$.
\end{abstract}

PACS. 21.10.Dr Binding energies and masses - 21.45.+v Few-body systems

The ${ }^{11} \mathrm{Li}$ is a two-neutron halo nuclide, consisting of a ${ }^{9} \mathrm{Li}$ core and two neutrons with a large spatial extension. The nuclide has a radius far beyond the droplet approximation [4], and has a very weak binding energy [5]. It is a Borromean three-body system, since the constituents cannot form bound two-body systems (i.e. ${ }^{10} \mathrm{Li}$ or the dineutron). This particular configuration represents a good test for theory to reproduce the three-body effect and to understand the neutron-neutron interaction. The two-neutron separation energy, derived from the mass, is a critical input parameter to modern three-body models, and gives a better idea of the weight of the $s$ and $p$-wave ground-state configuration of the two valence neutrons. It also constrains calculations based on the resonance energy of the unbound ${ }^{10} \mathrm{Li}$.

The MISTRAL experiment (Mass measurements at ISOLDE/CERN with a Transmission RAdiofrequency spectrometer on Line), determines the mass of short-lived nuclides by measuring their cyclotron frequency in a homogeneous magnetic field [6]. The ISOLDE beam is injected directely in the spectrometer alternately with an offline stable boron reference beam used to measure the magnetic field from its cyclotron frequency. With a resolving power up to $10^{5}$, we can reach a relative mass uncertainty of a few $10^{-7}$ for a production rate of 1000 ions/s. The accessible half-life is only limited by the time-of-flight of the ions through the beamline. The rapidity of this on-line method allows us to measure nuclides with $m s$ half-lives. ${ }^{11} \mathrm{Li}$ was provided by a tantalum thin-foil target and surface ionized [7] while the Laser Ion Source of the ISOLDE facility was used for Be beams.

Send offprint requests to: bachelet@csnsm.in2p3.fr

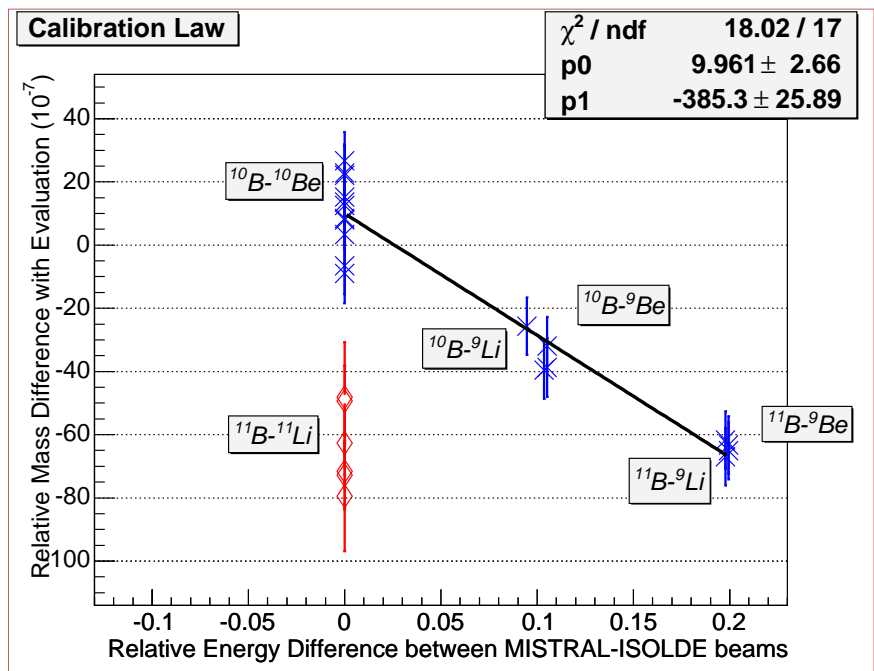

Fig. 1. Calibration law for the ${ }^{11} \mathrm{Li}$ run. The spectrometer was calibrated with 3 nuclei provided by ISOLDE target $\left({ }^{9,10} \mathrm{Be}\right.$ and ${ }^{9} \mathrm{Li}$ ), in comparison with ${ }^{10,11} \mathrm{~B}$ from the MISTRAL reference source. We used five combinations of these nuclides to determine the calibration law. Moreover, ${ }^{11} \mathrm{Li}$ measurements were added to show the difference.

In order to transmit the ISOLDE beam and the reference beam with the same magnetic field, the energy of the reference ions is adjusted in proportion. A deviation of the measurement with the mass from the AME $\left(\frac{m_{M I S T R A L}-m_{A M E}}{m_{A M E}}\right)$, proportional to the relative difference of the beam energies $\left(\frac{E_{I S O L D E}-E_{R e f}}{\bar{E}}\right)$ required a calibration law to correct the ${ }^{11} \mathrm{Li}$ measurement (see Fig. 1) [8]. 
Table 1. Summary of the different measurements of the ${ }^{11} \mathrm{Li}$ mass.

\begin{tabular}{ccc}
\hline Reference & Method & $S_{2 n}(\mathrm{keV})$ \\
\hline Thibault et al $[9]$ & Mass Spec. & $170 \pm 80$ \\
Wouters et al $[10]$ & TOF & $320 \pm 120$ \\
Kobayashi et al $[11]$ & ${ }^{11} \mathrm{~B}\left(\pi^{-}, \pi^{+}\right)^{11} \mathrm{Li}$ & $340 \pm 50$ \\
Young et al $[1]$ & ${ }^{14} \mathrm{C}\left({ }^{11} \mathrm{~B},{ }^{11} \mathrm{Li}\right)^{14} \mathrm{O}$ & $295 \pm 35$ \\
MISTRAL03 & Mass Spec. & $376 \pm 5$ \\
\hline
\end{tabular}

Table 2. Summary of the different measurements of the ${ }^{11} \mathrm{Be}$ mass.

\begin{tabular}{ccc}
\hline Reference & Method & Mass excess $(\mathrm{keV})$ \\
\hline Pullen et al $[2]$ & ${ }^{9} \mathrm{Be}(\mathrm{t}, \mathrm{p}){ }^{11} \mathrm{Be}$ & $20175 \pm 15$ \\
Gooseman et al $[3]$ & ${ }^{10} \mathrm{Be}(\mathrm{d}, \mathrm{p})^{11} \mathrm{Be}$ & $20174 \pm 7$ \\
MISTRAL03 & Mass Spec. & $20171 \pm 4$ \\
\hline
\end{tabular}

With the seven corrected measurements of ${ }^{11} \mathrm{Li}$, we have a preliminary measured value in comparison with the mass of AME95, $m_{M I S T R A L}-m_{A M E 95}=-75 \pm 5 \mathrm{keV}$.

The new measurement of ${ }^{11} \mathrm{Li}$ is seven times more precise than the value of Young et al. [1], having the dominant weight in the 1995 mass evaluation. Moreover, we find the mass more bound by $75 \mathrm{keV}$ compared to this value, with the ${ }^{14} \mathrm{C}\left({ }^{11} \mathrm{~B},{ }^{11} \mathrm{Li}\right){ }^{14} \mathrm{O}$ reaction (Tab. 1$)$. Though small, this represents a sizable shift in the two-neutron separation of more than $20 \%$. To make us sure of the value found, the mass of the ${ }^{11} \mathrm{Be}$ has been measured and be found nearly equal with the past one. Its precision has been improved by a factor near of two: $m_{M I S T R A L}-m_{A M E 95}=$ $-4 \pm 4 \mathrm{keV}$ (Tab. 2).

Yamashita et al. [12] have developed a zero-range interaction model in which the two-neutron separation energy is an input parameter to calculate the neutron-neutron distance in core- $n$ - $n$ halo nuclei as a function of the resonant energy of the core- $n$ unbound nuclei. This model reproduced well the experimental value of ${ }^{6} \mathrm{He}$ and ${ }^{14} \mathrm{Be}$ but not the one of ${ }^{11} \mathrm{Li}$ with the previous $S_{2 n}$. Calculations have been done with the new preliminary value [13] and the results are reported in Tab. 3 . The results are now in better agreement with the experimental value of Marqués et al. [14], and also for the $50 \mathrm{keV}{ }^{10} \mathrm{Li}$ resonant energy measured by Thoennessen et al. [15].

Recent results using nuclear field theory that include core polarization give ground state binding energies for ${ }^{11} \mathrm{Be}$ and ${ }^{12} \mathrm{Be}$ within a few percent $[16]$. For ${ }^{11} \mathrm{Li}$, their result $\left(S_{2 n}=360 \mathrm{keV}\right.$ [17]) was higher than that given by other models. As it turns out, their calculation is in excellent agreement with our higher $S_{2 n}$.

The MISTRAL measurement program on short-lived halo nuclides will be continued at ISOLDE for the cases of ${ }^{12,14} \mathrm{Be}$ and ${ }^{19} \mathrm{C}$. An upgrade to the spectrometer is in program to improve the sensitivity in order to match the extremely low production rates of these exotic nuclides [18].
Table 3. Different calculations of the neutron-neutron rms radii for ${ }^{11} \mathrm{Li}[12,13]$, with respectively $S_{2 n}=0.29 \mathrm{MeV}$ and $S_{2 n}=0.37 \mathrm{MeV}$, in function of the ${ }^{10} \mathrm{Li}$ virtual state energy. To compare the experimental value [14].

\begin{tabular}{cccc}
\hline $\begin{array}{c}\left.{ }^{11} \mathrm{Li}\right) S_{2 n} \\
(\mathrm{MeV})\end{array}$ & $\begin{array}{c}\left.{ }^{10} \mathrm{Li}\right) S_{n} \\
(\mathrm{keV})\end{array}$ & $\begin{array}{c}\sqrt{\left\langle r_{n n}^{2}\right\rangle} \\
(\mathrm{fm})\end{array}$ & $\begin{array}{c}\sqrt{\left\langle r_{n n}^{2}\right\rangle} \\
(\mathrm{fm})\end{array}$ \\
\hline 0.29 & 0 & 9.7 & $6.6 \pm 1.5$ \\
& -50 & 8.5 & \\
0.37 & 0 & 8.6 & $6.6 \pm 1.5$ \\
& -50 & 7.7 & \\
\hline
\end{tabular}

\section{References}

1. B.M. Young et al., Phys. Rev. Lett. 71, (1993) 4124.

2. D. Pullen et al., Nucl. Phys. 36, (1962) 1.

3. D. Gooseman and R. Kavanagh, Phys. Rev. C 1, (1970) 1939 .

4. I. Tanihata et al., Phys. Rev. Lett. 55, (1985) 2676.

5. G. Audi, A. Wapstra and C. Thibault, Nucl. Phys. A 279, (2003) 545.

6. D. Lunney et al., Phys. Rev. C 64, (2001) 054311.

7. J.R.J Bennett et al., Nucl. Instrum. Meth. Phys. Res. B 204, (2003) 215.

8. C. Bachelet, Ph.D Thesis, Université Paris XI, (2004).

9. C. Thibault et al., Phys. Rev. C 12, (1975) 644.

10. J.M. Wouters et al., Z. Phys. A 331, (1988) 229.

11. T. Kobayashi et al., KEK Report 91-22, (1991).

12. M.T. Yamashita, L. Tomio and T. Frederico, Nucl. Phys. A 735, (2004) 40.

13. M.T. Yamashita, L. Tomio and T. Frederico, Private communication, (2004).

14. F.M. Marqués et al., Phys. Rev. C 64, (2001) 061301.

15. M. Thoennessen et al., Phys. Rev. C 59, (1999) 111.

16. G. Gori et al., Phys. Rev. C 69, (2004) 041302.

17. R.A. Broglia et al., Proceedings of the International Nuclear Physics Conference 2001 (American Institute of Physics, 2002) 746.

18. M. Sewtz et al., to be published in Nucl. Instrum. Meth. Phys. Res. B 